(A) Check for updates

Cite this: Dalton Trans., 2019, 48 5505

Received 31st January 2019, Accepted 27th March 2019

DOI: $10.1039 / c 9 d t 00480 \mathrm{~g}$

rsc.li/dalton

\section{Interlinking supertetrahedral chalcogenolate clusters with bipyridines to form two-dimensional coordination polymers for photocatalytic degradation of organic dye $\uparrow$}

\author{
Chao Xu, (D)*a,b Ming-Ming Sheng, ${ }^{a}$ Hua-Tian Shi, ${ }^{a}$ Maria Strømme (D) ${ }^{b}$ and \\ Qian-Feng Zhang*a
}

\begin{abstract}
Chalcogenolate clusters $\mathrm{Cd}_{6} \mathrm{Ag}_{4}(\mathrm{EPh})_{16}(\mathrm{DMF})_{3}\left(\mathrm{CH}_{3} \mathrm{OH}\right)(\mathrm{E}=\mathrm{S}, \mathrm{Se})$ with supertetrahedral structures are isolated. Further interlinking the clusters with organic linker 4,4'-trimethylenedipiperidine in the stepwise assembly approach forms two-dimensional coordination polymers. The clusters and the coordination polymers show tunable band gaps and efficient photocatalytic activities for the degradation of aqueous dye solution. This study demonstrates the great potential of using chalcogenolate clusters and their coordination polymers in photocatalysis applications.
\end{abstract}

Supertetrahedral chalcogenide and chalcogenolate (SCC) clusters are of great current interest because of their unique molecular structures, size-dependent semiconducting properties, and photocatalytic behaviours. ${ }^{1-7}$ In particular, SCC clusters are capable of self-assembly with the formation of extended open-frameworks, exhibiting novel optical and electronic properties that are different from those of individual clusters and bulk chalcogenide materials. ${ }^{8,9}$ Vertex-linking of individual SCC clusters through the chalcogen atoms is a general assembly approach to build the extended frameworks, which have potential applications in fast-ion conductors, ${ }^{10}$ molecular sieves, ${ }^{11}$ semiconductors, ${ }^{12-16}$ photocatalysis, ${ }^{17}$ etc. In this context, a range of covalently bonded open-frameworks have been successfully constructed from various SCC clusters. For example, Feng and co-workers reported a range of $\mathrm{M}^{-} \mathrm{M}^{\prime}-\mathrm{E}$ $\left(\mathrm{M}=\mathrm{Ga}\right.$, In; $\mathrm{M}^{\prime}=\mathrm{Ge}, \mathrm{Sn} ; \mathrm{E}=\mathrm{S}$, Se) SCC clusters into zeolite analogs of microporous and photoluminescent chalcogenides, which are efficient visible-light photocatalysts for hydrogen

\footnotetext{
${ }^{a}$ Institute of Molecular Engineering and Applied Chemistry, Anhui University of Technology, Ma'anshan, Anhui, 243002, P. R. China.

E-mail: chao.xu0203@outlook.com,zhangqf@ahut.edu.cn

${ }^{b}$ Division of Nanotechnology and Functional Materials, Department of Engineering

Sciences, Uppsala University, Uppsala SE-75121, Sweden.

E-mail: chao.xu@angstrom.uu.se

$\dagger$ Electronic supplementary information (ESI) available: Details synthesis procedures and experimental methods, XRD patterns, IR spectra, TGA curves, extra table and figures. CCDC 1894746-1894749. For ESI and crystallographic data in CIF or other electronic format see DOI: 10.1039/c9dt00480g
}

generation from water. ${ }^{18,19}$ Kanatzidis and co-workers designed the reaction of SCC clusters $\left[\mathrm{M}_{4} \mathrm{E}_{10}\right]^{4-}(\mathrm{M}=\mathrm{Ge}, \mathrm{Sn}$; $\mathrm{E}=\mathrm{S}, \mathrm{Se}$ ) with $\mathrm{Pt}^{2+}$ and formed porous semiconducting gels and aerogels. ${ }^{20}$

On the other hand, the principles of coordination chemistry and reticular chemistry have been recently applied in the assembly of SCC clusters into coordination polymers, in which the SCC clusters are interlinked with multifunctional organic linkers. ${ }^{21-28}$ The integration of SCC clusters with organic linkers at the molecular level could lead to the formation of new structures as well as unique photochemical and photoelectric properties resulting from the synergetic effects. For example, Vaqueiro and co-workers reported on linking SCC clusters $\left[\mathrm{Ga}_{10} \mathrm{~S}_{16}\right]^{2-}$ with bipyridines for the design of covalent inorganic-organic networks, which present diverse architectures ranging from zero-dimensional (0D) clusters to onedimensional (1D) chains and two-dimensional (2D) layers and unique luminescent properties. ${ }^{29-31}$ Similarly, a new family of three-dimensional (3D) hybrid frameworks with semiconducting properties and permanent porosities were synthesized by the assembly of SCC clusters $\left[\operatorname{In}_{10} \mathrm{~S}_{16}\right]^{2-}$ or $\left[\operatorname{In}_{16} \mathrm{Cd}_{4} \mathrm{~S}_{31}\right]^{6-}$ with imidazole linkers. ${ }^{32}$ With this strategy, chalcogenolate clusters with other molecular shapes have also been assembled into functional coordination polymers. ${ }^{33,34}$ Therefore, the assembly of various chalcogenide or chalcogenolate clusters with organic linkers has greatly enriched the family of coordination polymers.

It is worth noting that most of the extended frameworks based on SCC clusters were synthesized under one-pot solvothermal conditions, in which the clusters were in situ formed and acted as nodes for the construction of extended frameworks. Therefore, it is difficult to control the synthesis of the in situ formed clusters and the overall frameworks by the onepot synthesis routes. Recently, we have developed a stepwise assembly approach for the design of semiconducting $1 \mathrm{D}$ and 3D coordination polymers by joining SCC clusters of $\mathrm{Cd}_{8} \mathrm{~S}$ $(\mathrm{SPh})_{14}(\mathrm{DMF})_{3}$ or $\mathrm{Cd}_{6} \mathrm{Ag}_{4}(\mathrm{SPh})_{16}(\mathrm{DMF})_{4}$ with rigid bipyridines. ${ }^{35,36}$ Obviously, the stepwise assembly approach offers 
opportunities for the design of such coordination polymers with tailored topologies and properties at the molecular level by controlling the molecular size and composition of the SCC clusters, shape and rigidity of the organic linkers, and their spatial arrangements. Herein, we present the stepwise assembly approach with the capability of dimensional control for the formation of 2D coordination polymers built from discrete clusters of $\mathrm{Cd}_{6} \mathrm{Ag}_{4}(\mathrm{EPh})_{16}(\mathrm{DMF})_{4}(\mathrm{E}=\mathrm{S}, \mathrm{Se})$ and a flexible ligand 4,4'-trimethylenedipiperidine (tmdp). The obtained hybrid materials show tunable band gaps and efficient photocatalytic activities for the degradation of organic dye in aqueous solution.

SCC clusters, serving as building blocks, have significant influences on the structures and properties of the corresponding coordination polymers. Therefore, it is highly desired to isolate different SCC clusters with well-defined structures and compositions as building blocks for the design of novel coordination polymers. Ternary SCC clusters are of great interest because of their unique heterometallic structures. Doping hetero-metal atoms into the binary clusters will change the coordination environment and bond structure of original metal-chalcogen bonds that may create ternary clusters with novel crystal structures and photoelectric properties. In comparison with binary SCC clusters, the synthesis of ternary SCC clusters is much more difficult due to the lack of suitable binary precursors. Until now, only a few types of ternary SCC clusters have been reported (e.g., $\quad\left[\mathrm{Cu}_{11} \mathrm{In}_{15} \mathrm{Se}_{16}(\mathrm{SePh})_{24}\left(\mathrm{PPh}_{3}\right)_{4}\right],{ }^{37}\left[\mathrm{Hg}_{6} \mathrm{Ag}_{4}(\mathrm{TePh})_{16}\right],{ }^{38}$ $\left.[\mathrm{Bmmim}]_{10}\left[\mathrm{NH}_{4}\right]_{3}\left[\mathrm{Cu}_{5} \mathrm{Ga}_{30} \mathrm{~S}_{52}(\mathrm{SH})_{4}\right]^{39}\right)$. Recently, we have attempted the reactions of metalloligands $\left(\mathrm{Me}_{4} \mathrm{~N}\right)_{2}\left[\mathrm{Cd}(\mathrm{EPh})_{4}\right]$ $(\mathrm{E}=\mathrm{S}, \mathrm{Se})$ with $\mathrm{M}\left(\mathrm{PPh}_{3}\right)_{2} \mathrm{NO}_{3}(\mathrm{M}=\mathrm{Cu}, \mathrm{Ag})$ and successfully isolated a number of ternary clusters of $\left[\mathrm{Cd}(\mu-\mathrm{EPh})_{4}\left\{\mathrm{M}\left(\mathrm{PPh}_{3}\right)_{2}\right\}_{2}\right]$ $(\mathrm{M}=\mathrm{S} \text {, Se; } \mathrm{M}=\mathrm{Cu}, \mathrm{Ag})^{40}$ and $\left[\mathrm{Cd}_{3}(\mathrm{EPh})_{10}\left(\mathrm{AgPPh}_{3}\right)_{4}\right](\mathrm{E}=$ $\mathrm{S}$, Se).$^{41}$ Interestingly, the reaction of a polymeric complex $\left[\mathrm{Cd}_{4}(\mathrm{SPh})_{8}\right]_{n}$ with $\mathrm{AgNO}_{3}$ in DMF afforded a ternary SCC cluster $\mathrm{Cd}_{6} \mathrm{Ag}_{4}(\mathrm{SPh})_{16}(\mathrm{DMF})_{4}(\mathbf{1 a})$ by slow evaporation of the DMF solution. ${ }^{36}$ In this study, we employ a different crystallization method by diffusing methanol into the DMF solution; a cluster $\mathrm{Cd}_{6} \mathrm{Ag}_{4}(\mathrm{SPh})_{16}(\mathrm{DMF})_{3}\left(\mathrm{CH}_{3} \mathrm{OH}\right)$ (1) is obtained. 1 contains the same core structure as $1 \mathrm{a}$, in which one of the vertexcoordinated DMF molecules in 1a is replaced by a methanol molecule in 1. Likewise, the reaction of $\left[\mathrm{Cd}_{4}(\mathrm{SePh})_{8}\right]_{n}$ with $\mathrm{AgNO}_{3}$ in DMF forms a ternary selenolate SCC cluster $\mathrm{Cd}_{6} \mathrm{Ag}_{4}(\mathrm{SePh})_{16}(\mathrm{DMF})_{3}\left(\mathrm{CH}_{3} \mathrm{OH}\right)$ (2), which is an isostructural of 1. Further reaction of $\mathbf{1}$ or $\mathbf{2}$ with tmdp in DMF results in novel coordination polymers $\mathrm{Cd}_{6} \mathrm{Ag}_{4}(\mathrm{EPh})_{16}(\mathrm{tmdp})_{2}(\mathrm{E}=\mathrm{S} \mathrm{3}$; Se 4). Scheme 1 summarizes the reactions of $\left(\mathrm{Me}_{4} \mathrm{~N}\right)_{2}\left[\mathrm{Cd}(\mathrm{EPh})_{4}\right]$ $(\mathrm{E}=\mathrm{S}, \mathrm{Se})$ and $\left[\mathrm{Cd}_{4}(\mathrm{EPh})_{8}\right]_{n}(\mathrm{E}=\mathrm{S}, \mathrm{Se})$ with coin metal complexes for the syntheses of the ternary chalcogenolate clusters and the stepwise assembly for the coordination polymers.

Obviously, the stepwise assembly approach applied in this study has several advantages compared with one-pot solvothermal reactions. First, the use of cluster 1 and 2 with welldefined crystal structures as building blocks allows prediction of molecular and topological structure of the obtained coordination polymers. In addition, the peripheral phenyl groups

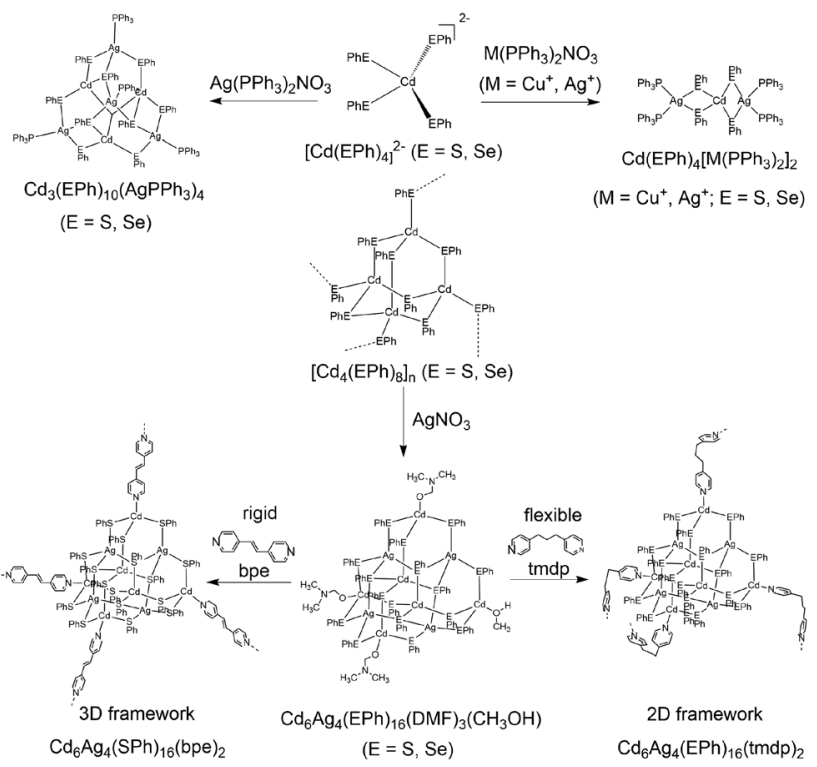

Scheme 1 Synthesis route of cadmium-silver (copper) thiolate and selenolate clusters and their assemblies with organic linkers.

and the coordinated solvent molecules not only stabilized the core structure of the clusters but also render them good solubility, which allows the reaction of the clusters with organic linkers in a solution process. Moreover, the four terminal coordinated solvent molecules in the clusters can be easily substituted by bipyridine ligands containing strong electron donors of $\mathrm{sp}^{2} \mathrm{~N}$ atoms. Given these advantages, two coordination polymers $\mathrm{Cd}_{6} \mathrm{Ag}_{4}(\mathrm{EPh})_{16}(\mathrm{tmdp})_{2}(\mathrm{E}=\mathrm{S} \mathrm{3}$; Se 4) were successfully synthesized by the stepwise assembly of cluster $\mathbf{1}$ and 2 with the flexible linker tmdp in DMF at room temperature.

The crystal structures of the clusters and the coordination polymers were determined by single crystal X-ray diffraction (XRD) analyses. In addition, powder XRD analyses have confirmed the purity of the synthesized crystals (ESI, Fig. S1 $\dagger$ ). The thiolate cluster $\mathbf{1}$ and the selenolate cluster $\mathbf{2}$ are isostructural, crystallized in the same space group $P \overline{1}$. As displayed in Fig. 1 and Fig. S2, $\uparrow$ the core structure of 1 consists of six cadmium and four silver atoms connected by twelve $\mu_{2}-\mathrm{PhS}^{-}$ and four $\mu_{3}-\mathrm{PhS}^{-}$moieties, while one methanol and three

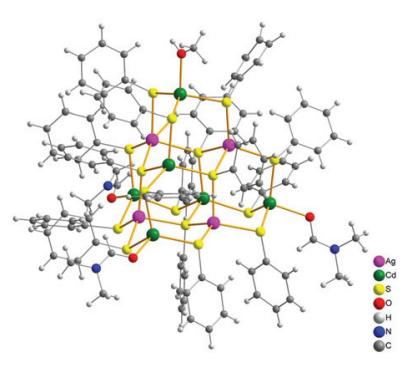

(a)

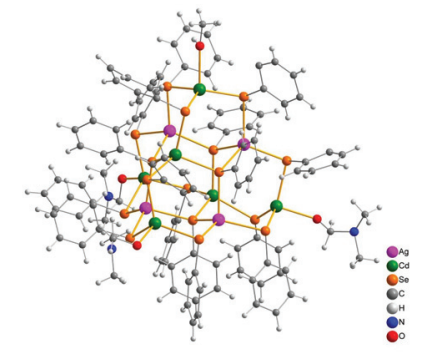

(b)
Fig. 1 Crystal structures of cluster (a) $\mathrm{Cd}_{6} \mathrm{Ag}_{4}(\mathrm{SPh})_{16}(\mathrm{DMF})_{3}\left(\mathrm{CH}_{3} \mathrm{OH}\right)$ (1) and (b) $\mathrm{Cd}_{6} \mathrm{Ag}_{4}(\mathrm{SePh})_{16}(\mathrm{DMF})_{3}\left(\mathrm{CH}_{3} \mathrm{OH}\right)(2)$. 
DMF molecules occupy the four terminal positions to form a supertetrahedral structure $\left(\mathrm{T} 3, \mathrm{M}_{10} \mathrm{X}_{20}\right) \cdot{ }^{42}$ All metal atoms locate in tetrahedral coordination environments. Each inner metal atom coordinates with four $\mathrm{S}$ atoms from two $\mu_{2}-\mathrm{PhS}^{-}$ and two $\mu_{3}-\mathrm{PhS}^{-}$groups, while each terminal metal atom bonds with three $\mathrm{S}$ atoms from three $\mu_{2}-\mathrm{PhS}^{-}$groups and one $\mathrm{O}$ atom from one solvent molecule, respectively. The average bond distances of $\mathrm{M}-\mu_{2}-\mathrm{SPh}$ and $\mathrm{M}-\mu_{3}-\mathrm{SPh}(\mathrm{M}=\mathrm{Cd}$ or $\mathrm{Ag})$ in 1 are 2.534 and $2.587 \AA$, respectively, which are slightly shorter than those of $\mathrm{M}-\mu_{2}-\operatorname{SePh}(2.650 \AA)$ and $\mathrm{M}-\mu_{3}-\operatorname{SePh}(2.686 \AA)$ in 2 because of the smaller atomic radius of $S$ than of Se, while the terminal $\mathrm{M}-\mathrm{O}$ bonds have much shorter average bond distance $(2.304 \AA$ in $1,2.403 \AA$ in 2$)$ than those of $\mathrm{M}-\mathrm{S} / \mathrm{Se}$. It should be noted that it is difficult to determine the precise positions of $\mathrm{Cd}$ and $\mathrm{Ag}$ in the clusters by X-ray crystallography because they are isoelectronic. However, we can estimate their positions by Paulling's second rule. ${ }^{43}$ To satisfy the electrostatic valence rule, each $\mu_{3}-\mathrm{EPh}^{-}(\mathrm{E}=\mathrm{S}, \mathrm{Se})$ group in the clusters should be surrounded by one cadmium and two silver atoms to give a band valence sum of 1 . Therefore, six inner metal sites are occupied by four silver atoms and two cadmium atoms with four possible arrangements, while four terminal metal positions are occupied by cadmium atoms. $^{36}$ Such arrangement was also found in several reported heterometallic SCCs, such as $\left.\left[\mathrm{Hg}_{6} \mathrm{Ag}_{4}(\mathrm{TePh})_{16}\right]\right]^{38}$ $\left\{\left[\mathrm{Cu}_{5} \mathrm{Ga}_{30} \mathrm{~S}_{52}(\mathrm{SH})_{4}\right]^{13-}\right\},{ }^{39}\left\{\left[\mathrm{In}_{16} \mathrm{Cd}_{4} \mathrm{~S}_{35}\right]^{14-}\right\}^{42}$ and $\left\{\left[\mathrm{M}_{4}\left(\mu_{4}-\mathrm{Se}\right)-\right.\right.$ $\left.\left.\left(\mathrm{SnSe}_{4}\right)_{4}\right]^{10-}\right\}(\mathrm{M}=\mathrm{Zn}, \mathrm{Mn}),{ }^{44}$ in which metal atoms with lower valence were located inside the structures.

Coordination polymer $\mathbf{3}$ and $\mathbf{4}$ are isostructural, crystallized in the same space group $C 2 / c$. The thiolate cluster $\mathbf{1}$ and the selenolate cluster 2 served as secondary building units in 3 and $\mathbf{4}$, respectively, while tmdp interlinked the clusters to form the coordination polymers. The linker tmdp usually has four different configurations (TT, TG, GG and GG' $)^{45}$ because of the flexible and rotatable trimethylene $-\left(\mathrm{CH}_{2}\right)_{3}-$ chain. In the case of 3 and 4 , it adopted a TG configuration with an average $\mathrm{N} \cdots \mathrm{N}$ distance of $8.451 \AA$ and resulted in the $(4,4)$-connected $2 \mathrm{D}$ open frameworks (Fig. 2). In comparison, the use of a rigid and linear linker of trans-1,2-bis(4-pyridyl)ethane (bpe) interlinking cluster 1a resulted in a 3D diamond-like structure of $\mathrm{Cd}_{6} \mathrm{Ag}_{4}(\mathrm{SPh})_{16}(\mathrm{DMF})_{4}(\mathrm{bpe})_{2}$, which was reported in our previous study. ${ }^{36}$ Theoretically, tuning the molecular ratio between the cluster and the linear linker that form subunits of two- and one-connected clusters could construct $1 \mathrm{D}$ and $0 \mathrm{D}$ coordination polymers, respectively. Fig. 2 shows the crystal structures of coordination polymer 3 and 4 . Each cluster in 3 is four-connected by tmdp linkers through the coordination bonds of Cd (cluster)-N (tmdp) with an average bond distance of $2.336 \AA$. As a result, a wavelike $(4,4)$-connected network is formed. The single network shows a zig-zag chain structure from the side view in the $a$ direction, while it represents a straight chain structure containing channels from the side view in the $b$ direction. Meanwhile, the overall framework consists of two-fold interpenetrated layers (Fig. 3). Because of the large molecular size of the clusters, the distances between the layers in 3 and $\mathbf{4}$ are 27.496 and $28.122 \AA$, respectively, which are significantly larger than those of other $2 \mathrm{D}$ materials, such as graphite $(3.35 \AA)$, layered metal-organic framework $\left[\mathrm{Cu}\left(\mathrm{BF}_{4}\right)_{2}(\mathrm{bpy})_{2}\right]$ (bpy $=4,4^{\prime}$-bipyridine) $(4.6 \AA),{ }^{46}$ and covalent organic framework-LZU1 $(3.7 \AA) .{ }^{47}$ The large layer distance in 3 and 4 indicates the weak interactions between the layers that may facilitate exfoliation of the bulky materials into single- or few-layer nanosheets for the design of novel 2D nanomaterials.

Thermogravimetric analysis (ESI, Fig. S4†) indicates that cluster 1 is stable up to $320{ }^{\circ} \mathrm{C}$. The high thermal stability of cluster 1 can be attributed to the relatively strong covalent bonds of metal-sulphur. In comparison, coordination polymer 3 possesses a lower thermal stability because of the weaker coordination bonds between the clusters and the linkers (Fig. S4 $\dagger$ ). It started to decompose at $200{ }^{\circ} \mathrm{C}$ and the weight loss between 200 and $280{ }^{\circ} \mathrm{C}$ can be ascribed to the decomposition of the organic components of phenyl groups and tmdp

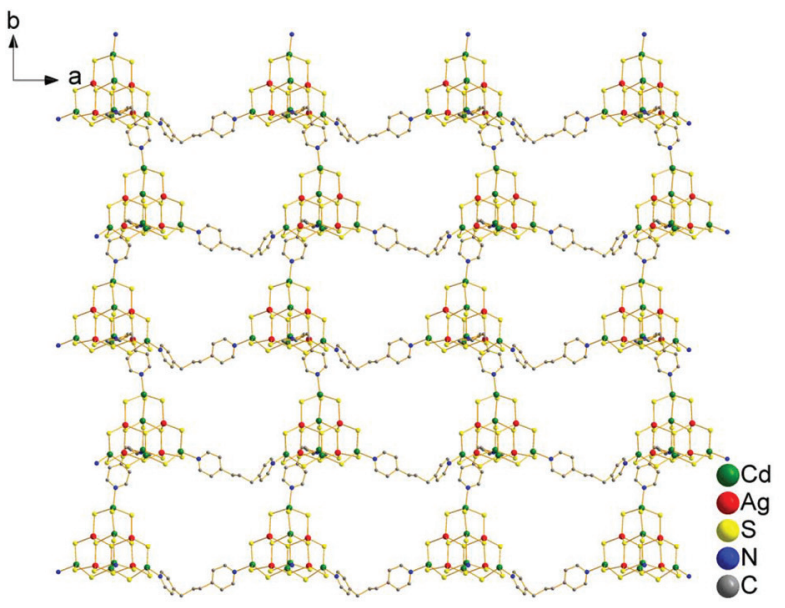

(a)

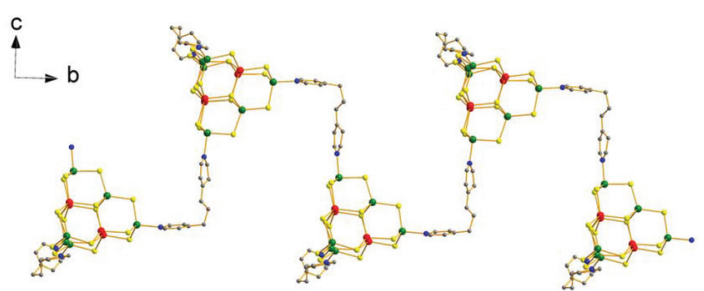

(b)

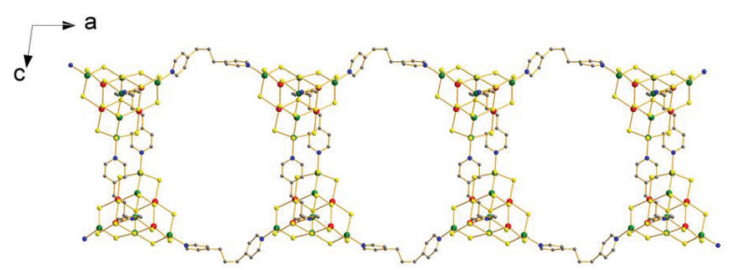

(c)

Fig. 2 View of the $2 \mathrm{D}$ network of coordination polymer $\mathrm{Cd}_{6} \mathrm{Ag}_{4}(\mathrm{SPh})_{16}(\mathrm{DMF})_{4}(\mathrm{tmdp})_{2}(3)$ from different directions. 


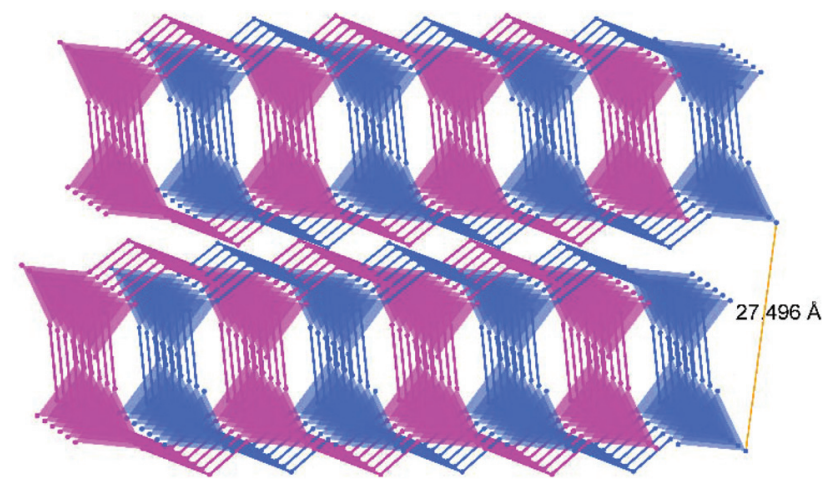

Fig. 3 The two-fold interpenetrated network in coordination polymer 3 and its inter-layer structure.

molecules. The further weight loss between 280 and $440{ }^{\circ} \mathrm{C}$ can be attributed to the decomposition of core structure of the cluster with the loss of sulphur species. The thermal decomposition residues of 1 and 3 were analysed by XRD (ESI, Fig. S5 $\dagger$ ) and determined to be ternary compounds of CdS-Ag, suggesting that the clusters and the coordination polymers can be employed as single precursors for the preparation of corresponding ternary $\mathrm{Cd}-\mathrm{S}-\mathrm{Ag}$ nanocrystals.

The optical absorption spectra of the clusters $(\mathbf{1}, \mathbf{2})$ and the coordination polymers $(3,4)$ were measured in the solid-state using a diffuse-reflectance method. As shown in Fig. 4, the thiolate cluster 1 has an adsorption onset at $400 \mathrm{~nm}$ and the onset of the selenolate cluster 2 shifts to a larger wavelength of $426 \mathrm{~nm}$, indicating that they are semiconductors with bandgaps of 3.10 and $2.91 \mathrm{eV}$, respectively. The red-shift from the thiolate to the selenolate cluster was observed in other chalcogenolate clusters ${ }^{48}$ and their bulk materials (CdS: $2.42 \mathrm{eV}$; CdSe: $1.70 \mathrm{eV}$ ). Compared with the isolated clusters, the corresponding coordination polymers $\mathbf{3}$ and $\mathbf{4}$ show much greater absorptions with red-shifted absorption onsets of $408 \mathrm{~nm}$ $(3.04 \mathrm{eV})$ and $441 \mathrm{~nm}$ (2.81 eV), respectively, which can be

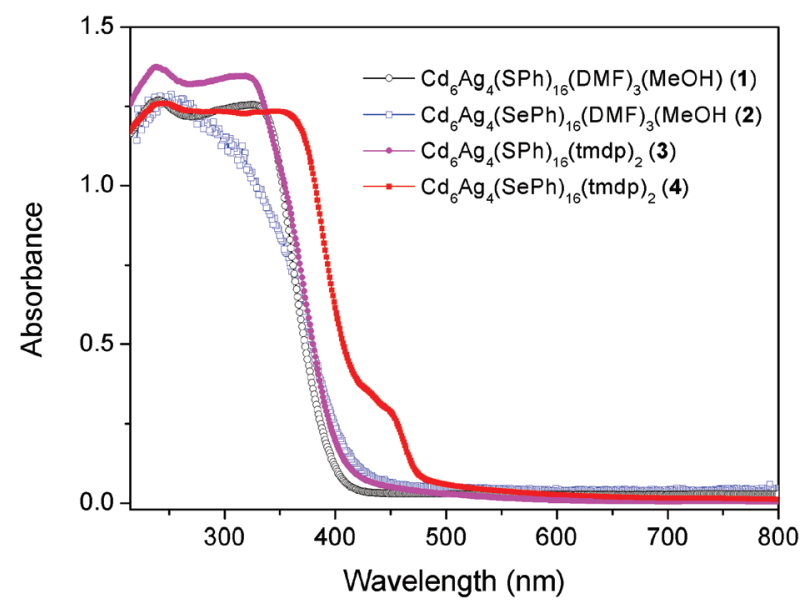

Fig. 4 Solid-state UV/vis diffuse spectra of the clusters and the coordination polymers. attributed to the charge transfer between the clusters and tmdp linkers. It clearly shows that the band gap of such hybrid coordination polymer is mainly dependent on the molecular structure, size, composition of the clusters and the type of organic linkers, suggesting that it is possible to finely tune the band gap by control of the clusters and the linkers.

On the basis of the semiconducting behaviours and strong $\mathrm{UV} / \mathrm{vis}$ absorption of the clusters and the coordination polymers, we expect them to be active photocatalysis materials. Hence, they were tested as heterogeneous photocatalysts for degradation of rhodamine $\mathrm{B}(\mathrm{RhB})$ in an aqueous solution. The catalyst was first mixed with the dye solution and then illuminated by visible light. As expected, the red dye solution quickly faded to pink and finally turned to colourless. Fig. 5 illustrates the results of the photocatalytic degradation experiment. Coordination polymer $\mathbf{3}$, based on thiolate cluster,

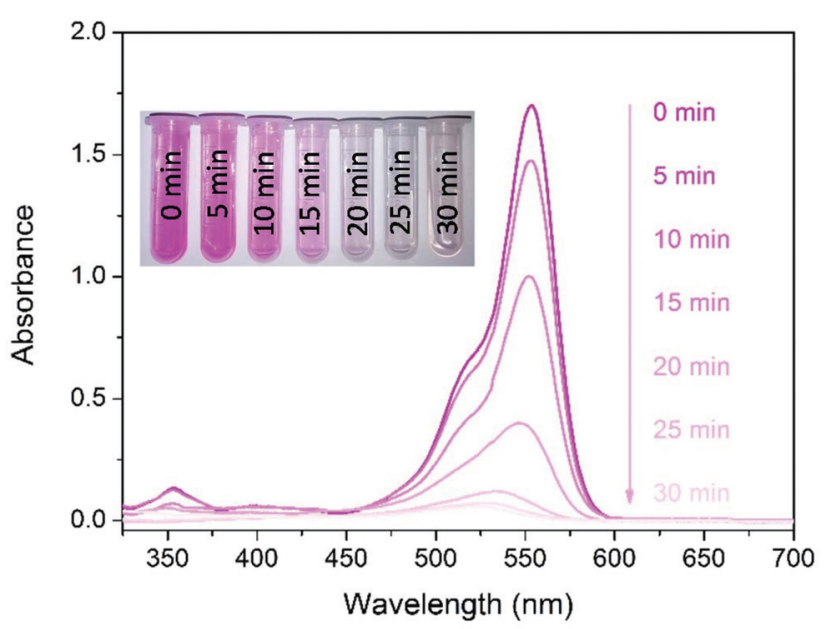

(a)

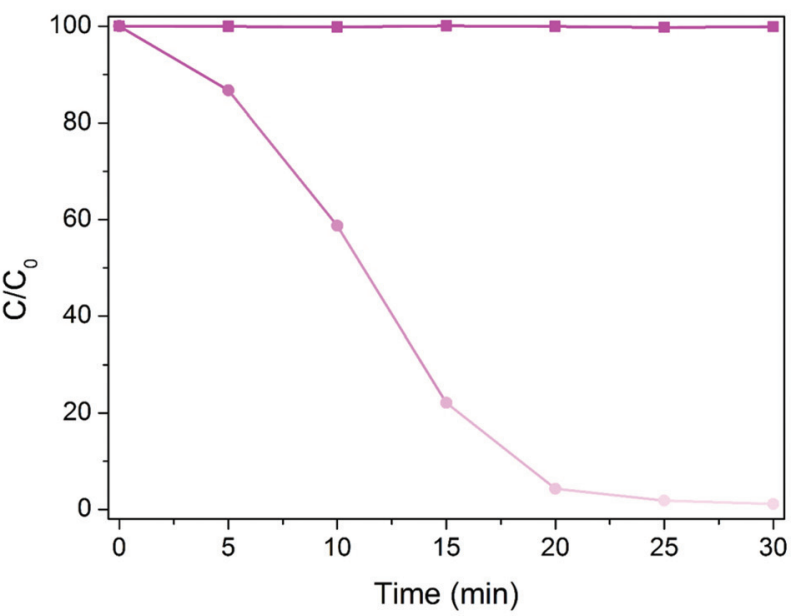

(b)

Fig. 5 (a) UV/vis spectra and optical images of the aqueous rhodamine $B$ during the degradation process photocatalyzed by coordination polymer 3; (b) concentration changes of rhodamine B during the photocatalysis process. The concentration of rhodamine $\mathrm{B}$ was calculated from the UV/vis absorbance at $555 \mathrm{~nm}$. 
reduced the concentration of $\mathrm{RhB}$ by $98 \%$ after illumination for $30 \mathrm{~min}$. In contrast, no degradation was observed in the absence of the catalyst. Noteworthy, the characteristic absorption band of RhB at $555 \mathrm{~nm}$ was gradually blue-shifted to $526 \mathrm{~nm}$ during the photocatalytic process, which can be explained by the decomposition of the conjugated structure of RhB molecules. ${ }^{49}$ Given the wider visible absorption of $\mathbf{4}$ than of 3 , we expected that 4 could be a more efficient photocatalyst. However, $\mathbf{4}$ is less active than $\mathbf{3}$ for the photocatalytic degradation of RhB (ESI, Fig. S6 $\dagger$ ). Under the same photocatalytic conditions, 4 only reduced the RhB concentration by $70 \%$ after illumination for $30 \mathrm{~min}$ and that it took up to $150 \mathrm{~min}$ to remove $95 \%$ of the dye molecules from the solution. The relatively low photocatalytic efficiency of $\mathbf{4}$ can probably be attributed to the weak water-stability of the selenolate cluster and the corresponding coordination polymer. In addition, the stability and the cycle performance of the catalysts were evaluated under the photocatalysis conditions. It was found that the crystalline structure of the catalyst $\mathbf{1}$ was significantly affected during the photocatalysis test that the ternary cluster probably converted into individual cadmium and silver thiolate compounds (Fig. S7a †). Noteworthy, the recycled catalyst retained efficient photocatalytic activity, indicating good cycle performance of the catalyst for photocatalytic degradation of the dye solution (Fig. S7b †

To conclude, ternary cadmium-silver-thiolate and -selenolate clusters with supertetrahedral shapes were isolated and further interlinked with bipyridines for the formation of novel coordination polymers exhibiting semiconducting and photocatalytic behaviours. The stepwise assembly method applied in this study offers opportunities to control the spatial arrangement, dimension, and relevant properties of the coordination polymers. The band gap of the coordination polymers were significantly influenced by the composition and structure of the cluster as well as the molecular structure of the linker. In this context, the band gap of such coordination polymers can be finely controlled by the molecular engineering approach. Future studies may focus on the design of photocatalytic and photoelectric devices based on these clusters and coordination polymers to exploit their practical applications. This study may open up an avenue for the development of novel functional semiconducting materials and devices using chalcogenolate clusters and their coordination polymers.

\section{Conflicts of interest}

There are no conflicts to declare.

\section{Acknowledgements}

This work was supported by the National Science Foundation of China (90922008) and Young Wanjiang Scholar program of Anhui Province.

\section{Notes and references}

1 J. F. Corrigan, O. Fuhr and D. Fenske, Adv. Mater., 2009, 21, 1867-1871.

2 G. S. H. Lee, D. C. Craig, I. Ma, M. L. Scudder, T. D. Bailey and I. G. Dance, J. Am. Chem. Soc., 1988, 110, 4863-4864.

3 N. Herron, J. C. Calabrese, W. E. Farneth and Y. Wang, Science, 1993, 259, 1426-1428.

4 S. Behrens, M. Bettenhausen, A. Eichhöfer and D. Fenske, Angew. Chem., Int. Ed. Engl., 1997, 36, 2797-2799.

5 N. Zheng, X. Bu, H. Lu, Q. Zhang and P. Feng, J. Am. Chem. Soc., 2005, 127, 11963-11965.

6 T. I. Levchenko, C. Kübel, Y. Huang and J. F. Corrigan, Chem. - Eur. J., 2011, 17, 14394-14398.

7 L. Nie and Q. Zhang, Inorg. Chem. Front., 2017, 4, 1953-1962.

$8 \mathrm{X} . \mathrm{Bu}, \mathrm{N}$. Zheng and P. Feng, Chem. - Eur. J., 2004, 10, 3356-3362.

9 P. Feng, X. Bu and N. Zheng, Acc. Chem. Res., 2005, 38, 293303.

10 N. Zheng, X. Bu and P. Feng, Nature, 2003, 426, 428-432.

11 C. Xue, D. Hu, Y. Zhang, H. Yang, X. Wang, W. Wang and T. Wu, Inorg. Chem., 2017, 56, 14763-14766.

12 J. Lin, Y. Dong, Q. Zhang, D. Hu, N. Li, L. Wang, Y. Liu and T. Wu, Angew. Chem., 2015, 127, 5192-5196.

13 Q. Zhang, X. Bu, J. Zhang, T. Wu and P. Feng, J. Am. Chem. Soc., 2007, 129, 8412-8413.

14 Q. Zhang, Y. Liu, X. Bu, T. Wu and P. Feng, Angew. Chem., Int. Ed., 2008, 47, 113-116.

15 Q. Zhang, I. Chung, J. I. Jang, J. B. Ketterson and M. G. Kanatzidis, Chem. Mater., 2009, 21, 12-14.

16 Q. Zhang, T. Wu, X. Bu, T. Tran and P. Feng, Chem. Mater., 2008, 20, 4170-4172.

17 K. Sasan, Q. Lin, C. Mao and P. Feng, Nanoscale, 2016, 8, 10913-10916.

18 N. Zheng, X. Bu, B. Wang and P. Feng, Science, 2002, 298, 2366-2369.

19 N. Zheng, X. Bu, H. Vu and P. Feng, Angew. Chem., Int. Ed., 2005, 44, 5299-5303.

20 S. Bag, P. N. Trikalitis, P. J. Chupas, G. S. Armatas and M. G. Kanatzidis, Science, 2007, 317, 490-493.

21 P. Vaqueiro, Dalton Trans., 2010, 39, 5965-5972.

22 N. Zheng, X. Bu, H. Lu, L. Chen and P. Feng, J. Am. Chem. Soc., 2005, 127, 14990-14991.

23 Z. Chen, D. Luo, X. Luo, M. Kang and Z. Lin, Dalton Trans., 2012, 41, 3942-3944.

24 C. Xu, Y.-G. Han, T. Duan, Q.-F. Zhang and W.-H. Leung, Inorg. Chem. Commun., 2009, 12, 1053-1056.

25 N. Zheng, X. Bu, J. Lauda and P. Feng, Chem. Mater., 2006, 18, 4307-4311.

26 L.-D. Lin, D. Zhao, X.-X. Li and S.-T. Zheng, Chem. - Eur. J., 2019, 25, 442-453.

27 H. Yang, J. Zhang, M. Luo, W. Wang, H. Lin, Y. Li, D. Li, P. Feng and T. Wu, J. Am. Chem. Soc., 2018, 140, 1118911192.

28 Q. Zhang, X. Bu, Z. Lin, T. Wu and P. Feng, Inorg. Chem., 2008, 47, 9724-9726. 
29 P. Vaqueiro and M. L. Romero, Inorg. Chem., 2009, 48, 810812.

30 P. Vaqueiro, M. L. Romero, B. C. Rowan and B. S. Richards, Chem. - Eur. J., 2010, 16, 4462-4465.

31 P. Vaqueiro and M. L. Romero, J. Am. Chem. Soc., 2008, 130, 9630-9631.

32 T. Wu, R. Khazhakyan, L. Wang, X. Bu, S.-T. Zheng, V. Chau and P. Feng, Angew. Chem., Int. Ed., 2011, 50, 2536-2539.

33 R.-W. Huang, X.-Y. Dong, B.-J. Yan, X.-S. Du, D.-H. Wei, S.-Q. Zang and T. C. W. Mak, Angew. Chem., 2018, 130, 8696-8702.

34 R.-W. Huang, Y.-S. Wei, X.-Y. Dong, X.-H. Wu, C.-X. Du, S.-Q. Zang and T. C. W. Mak, Nat. Chem., 2017, 9, 689-697.

35 C. Xu, N. Hedin, H.-T. Shi, Z. Xin and Q.-F. Zhang, Dalton Trans., 2015, 44, 6400-6405.

36 C. Xu, N. Hedin, H.-T. Shi and Q.-F. Zhang, Chem. Commun., 2014, 50, 3710-3712.

37 A. Eichhöfer and D. Fenske, J. Chem. Soc., Dalton Trans., 2000, 941-944.

38 D. F. Back, G. N. M. de Oliveira, R. A. Burrow, E. E. Castellano, U. Abram and E. S. Lang, Inorg. Chem., 2007, 46, 2356-2358.
39 W.-W. Xiong, J.-R. Li, B. Hu, B. Tan, R.-F. Li and X.-Y. Huang, Chem. Sci., 2012, 3, 1200-1204.

40 C. Xu, J.-J. Zhang, T.-K. Duan, Q. Chen, W.-H. Leung and Q.-F. Zhang, Polyhedron, 2012, 33, 185-193.

41 C. Xu, J.-J. Zhang, Q. Chen, T. Duan, W.-H. Leung and Q.-F. Zhang, Inorg. Chem. Commun., 2012, 15, 308-310.

42 H. Li, J. Kim, T. L. Groy, M. O'Keeffe and O. M. Yaghi, J. Am. Chem. Soc., 2001, 123, 4867-4868.

43 L. Pauling, J. Am. Chem. Soc., 1929, 51, 1010-1026.

44 S. Dehnen and M. K. Brandmayer, J. Am. Chem. Soc., 2003, 125, 6618-6619.

45 L. Carlucci, G. Ciani, D. M. Proserpio and S. Rizzato, CrystEngComm, 2002, 4, 121-129.

46 A. Kondo, H. Noguchi, S. Ohnishi, H. Kajiro, A. Tohdoh, Y. Hattori, W.-C. Xu, H. Tanaka, H. Kanoh and K. Kaneko, Nano Lett., 2006, 6, 2581-2584.

47 S.-Y. Ding, J. Gao, Q. Wang, Y. Zhang, W.-G. Song, C.-Y. Su and W. Wang, J. Am. Chem. Soc., 2011, 133, 19816-19822.

48 A. Eichhöfer, A. Aharoni and U. Banin, Z. Anorg. Allg. Chem., 2002, 628, 2415-2421.

49 P. Lei, C. Chen, J. Yang, W. Ma, J. Zhao and L. Zang, Environ. Sci. Technol., 2005, 39, 8466-8474. 